\title{
Índice meiótico e palinologia de cerejeira-do-mato (Eugenia involucrata DC-Myrtaceae)
}

\author{
Meiotic index and palynology of Eugenia involucrata DC-Myrtaceae
}

Lohanna Baltar Pinto de Oliveira \& Patrícia Maria Oliveira Pierre*

Universidade Federal de Santa Catarina, Curitibanos, SC, Brasil. *Autor para correspondência: patgenpierre@gmail.com.

Submissão: 10/11/2017 | Aceite: 13/06/2018

\begin{abstract}
RESUMO
O índice meiótico e a palinologia foram realizados para a cerejeira-do-mato (Eugenia involucrata DCMyrtaceae), uma espécie nativa do sul do Brasil que apresenta frutos que podem ser destinados à agroindústria, além de potencial biotecnológico devido às suas propriedades medicinais. Botões florais oriundos de diferentes indivíduos de uma população localizada no município de Campo Erê, Santa Catarina, Brasil, foram coletados e fixados. Anteras em distintos estágios de desenvolvimento foram submetidas a diferentes técnicas para a obtenção de células meióticas e grãos de pólen. As células meióticas, em diferentes estágios do ciclo celular, apresentaram um comportamento cromossômico normal. Os indivíduos analisados apresentaram índices meióticos superiores a 95\%, indicando estabilidade citológica. Os grãos de pólen apresentaram-se amido-positivos e lipídeo negativos e percentuais de viabilidade polínica superiores a $95 \%$ em todos os testes colorimétricos. A espécie apresenta grãos caracterizados como mônades, pequenos, oblatos, tricolporados, sincolpados e ornamentação verrucada. A alta estabilidade meiótica, a presença de substâncias de reserva e a morfologia polínica evidenciadas no presente estudo possuem importantes implicações para a escolha de materiais genéticos potenciais para o melhoramento genético, para o entendimento de mecanismos de polinização na biossistemática do gênero.
\end{abstract}

PALAVRAS-CHAVE: Meiose, grãos de pólen, Myrteae.

\begin{abstract}
Meiotic index and palynology were assessed for Eugenia involucrata DC-Myrtaceae, a native species of southern Brazil that presents fruits with commercial potential and medicinal properties. For this purpose, floral buds were collected of different individuals from one population at Campo Erê, Santa Catarina, Brazil, and fixed for analysis. Anthers at different development stages were subjected to several techniques for analysis of meiocytes and pollen grains. The behavior of chromosomes in meiosis was normal, with cells in several phases of the cell cycle. Analysis of meiotic index allowed high cytological stability, with $95 \%$ of regular tetrads. The pollen grains were positive-starch and negative-lipid. The pollen viability was higher than $95 \%$ in all colorimetric tests. Pollen grains are monads, small, oblate, tricolporate, syncolpate with verrucate ornamentation of exine. The high meiotic stability, presence of reserve substances and pollen morphology evidenced in this study have important implications in the selection of potential genetic material for plant breeding, the understanding of pollinating mechanisms and the biosystematics of the genus.
\end{abstract}

KEYWORDS: meiosis, pollen grains, Myrteae.

\section{INTRODUÇÃO}

A família Myrtaceae apresenta espécies de expressiva representatividade dos biomas brasileiros, sendo algumas utilizadas na medicina popular para o tratamento de distúrbios gastrointestinais, estados hemorrágicos e doenças infecciosas. Trata-se de uma das famílias botânicas mais conhecidas, devido ao potencial biotecnológico de espécies nativas, com frutos em condições para a industrialização, que apresentam bom rendimento em polpa, aroma característico e presença de compostos fitoquímicos com propriedades antioxidantes (CAMLOFSKI 2008). Esta compreende aproximadamente 142 gêneros e mais de 5.500 espécies, com distribuição pantropical, havendo dois principais centros de diversidade, América 
tropical e Austrália (HEYWOOD et al. 2007, WILSON 2011). No Brasil, a família das mirtáceas é composta por 23 gêneros e 1028 espécies, de alto potencial a ser explorado como espécies ornamentais ou com destino à produção comercial de frutos. Entre os gêneros da família, destaca-se a Eugenia, o maior gênero americano distribuído principalmente do México ao Uruguai, com algumas espécies africanas e asiáticas (HARON \& MOORE 1996, SÁNCHEZ-VINDAS et al. 2001, VAN DER MERWE et al. 2005). No Brasil, configura-se como um dos maiores gêneros, abrangendo aproximadamente 384 espécies (SOBRAL et al. 2015). Espécies desse gênero apresentam valor comercial, nutritivo e potencial de aproveitamento na obtenção de fármacos (REGO et al. 2006). Além disso, algumas espécies também podem ser utilizadas em programas de recuperação de áreas degradadas e de conservação permanente, por apresentarem frutos amplamente consumidos pela avifauna, o que auxilia na dispersão das sementes (DEGENHARDT et al. 2007).

Um exemplo de espécie com diversas potencialidades é a Eugenia involucrata DC, popularmente conhecida como cerejeira-do-mato ou cerejeira-do-Rio Grande, nativa do sul do Brasil, que apresenta elevado potencial econômico a ser explorado, em virtude principalmente das características organolépticas dos seus frutos, sendo estes, destinados ao consumo in natura ou à produção de licores e geleias pela agroindústria, e ainda, por sua possível utilização para produção de fitoterápicos (CAMLOFSKI 2008).

Vale a pena ressaltar que embora apresente potencial agronômico, essa espécie ainda permanece subutilizada uma vez que o setor frutícola nacional, em sua maioria, ainda tem direcionado suas ações ao cultivo de espécies exóticas que são adaptadas a condições climáticas do país. De acordo com PRADO (2009), E. involucrata vem sendo cultivada somente em pomares domésticos nas regiões Sul e Sudeste do Brasil. No entanto, no exterior, a produção da cerejeira-do-mato, denominada de E. aggregata (SHARPE et al. 1996, LORENZI et al. 2006) é significativa.

Associada à sua baixa exploração comercial, dados meióticos e palinológicos são escassos para $E$. involucrata. Tais estudos são importantes por fornecerem bases a programas de melhoramento genético e proporcionarem um melhor entendimento sobre aspectos reprodutivos, ecológicos e biossistemáticos.

A estabilidade meiótica e a produção de gametas viáveis são aspectos diretamente associados à reprodução e manutenção das plantas dessas espécies por meio de sementes. A identificação de genótipos mais estáveis mediante a análise do índice meiótico permite, portanto, o planejamento de programas de produção de sementes das cultivares em vias de lançamento, como também, auxilia na eventual utilização destes, para a produção de novas populações (POZZOBON et al. 2011).

Análises de estabilidade meiótica associadas à observação da viabilidade polínica permitem indicar o potencial de cruzamento das plantas, auxiliando na seleção de materiais genéticos e fazer inferências sobre a eficiência de cruzamentos (DIEGUES et al. 2015). Além disso, avaliações do comportamento meiótico constituem de poderosas ferramentas em estudos evolutivos, bem como na escolha de genótipos a serem utilizados em programas de melhoramento genético, uma vez que, permite que indivíduos sejam avaliados quanto à sua estabilidade genética e fertilidade, auxiliando na seleção dos genótipos de interesse (GRANATO 2010).

Os grãos de pólen asseguram o direcionamento dos gametas masculinos ao saco embrionário durante a reprodução sexual em plantas. Consistem de estruturas que possuem uma parede celular complexa, cuja camada mais externa, denominada exina, é ornamentada seguindo um modelo espécieespecífico (BEDINGER 1992), sendo, portanto, utilizada, juntamente com outros caracteres morfológicos polínicos tais como o tamanho, a forma, o agrupamento, a simetria, a polaridade, o número e o tipo de aberturas, como caracteres taxonômicos. De acordo com BLACKMORE (2007), o principal atributo que torna os grãos de pólen muito informativos taxonomicamente é o simples fato de que eles podem apresentar variações em sua morfologia. Esta variação é herdável e mostra um alto nível de consistência dentro de um táxon.

Além disso, o citoplasma dos grãos de pólen maduros pode conter substâncias de reserva, tais como carboidratos e lipídeos (NEPI \& FRANCHI 2000). Tais moléculas podem ser evidenciadas por meio de técnicas citoquímicas e sua presença possui um significado para a reprodução e ecologia das espécies de plantas, influenciando na sua viabilidade, no tipo de polinização, na eficiência na dispersão, na proteção contra a perda de água e contra radiação UV (BAKER \& BAKER 1979, NEPI \& FRANCHI 2000, RODRÍGUEZ-GARCÍA et al. 2003, WANG et al. 2004, PACINI \& HESSE 2005, PACINI et al. 2006).

Considerando a espécie $E$. involucrata, poucos estudos foram realizados nesse sentido. Dados sobre o comportamento meiótico da espécie foram relatados por GUERRA et al. (2016), que avaliaram acessos provenientes do Rio Grande do Sul que apresentaram um percentual 82,12\% de células meióticas normais, além de $92,44 \%$ de grãos de pólen viáveis, quando analisados por meio de técnicas de colorimetria. 
Informações a respeito da morfologia polínica de espécies do gênero foram realizadas por WYK \& DEDEKIND (1985) que relataram o valor taxonômico da morfologia dos grãos de pólen para 14 espécies africanas. No Brasil, os únicos relatos a respeito da morfologia polínica para a espécie foram realizados por BARTH \& BARBOSA (1972) e TAKEDA et al. (2002), que descreveram a morfologia polínica de $E$. involucrata em catálogos polínicos a partir de espécimes ocorrentes em Santa Catarina e no Parque Estadual de Vila Velha- Paraná, respectivamente. Além disso, STANSKI (2014) realizou a análise da morfologia polínica de diferentes espécies do gênero ocorrentes no estado do Paraná, incluindo $E$. arenosa, E. handroana, E. hiemalis, E. pitanga, E. punicifolia e E. uniflora.

Dados citoquímicos, que evidenciem a presença de componentes de reserva específicos em grãos de pólen são importantes para o entendimento de aspectos ecológicos relacionados a mecanismos de polinização. Dados dessa natureza para a espécie são inexistentes na literatura, o que evidencia a importância desses estudos para E. involucrata.

Com relação à viabilidade polínica, foram relatados dados sobre acessos de E. involucrata provenientes do Rio Grande do Sul, nos quais foi analisada a viabilidade polínica por meio da coloração com carmim propiônico e por meio de germinação dos grãos de pólen in vitro (FRANZON \& RASEIRA 2004, GUERRA et al. 2016).

Informações sobre a citoquímica, a viabilidade e a morfologia dos grãos de pólen podem fornecer esclarecimentos a respeito da propagação da espécie auxiliando em programas de melhoramento, na conservação dos seus recursos genéticos, bem como na elucidação de características que propiciem um melhor entendimento taxonômico e biossistemático.

Diante do exposto, o presente trabalho teve por objetivo realizar um estudo reprodutivo, com enfoques na determinação do índice meiótico e na caracterização aspectos morfológicos e citoquímicos dos grãos de pólen de $E$. involucrata provenientes do estado de Santa Catarina, a fim de obter informações que poderão colaborar com futuros programas de melhoramento e conservação de recursos genéticos, bem como auxiliar na biossistemática do gênero.

\section{MATERIAL E MÉTODOS}

Botões florais em diferentes estágios de desenvolvimento foram coletados de quatro indivíduos de cerejeira-do-mato presentes em uma propriedade rural situada no município de Campo Erê, no estado de Santa Catarina, Brasil. Estas foram fixadas em Carnoy (etanol: ácido acético 3:1). Posteriormente, os materiais foram levados ao laboratório de Biologia Celular e para o Laboratório Central de Microscopia Eletrônica (LCME), da Universidade Federal de Santa Catarina, Campus de Curitibanos e Campus Trindade, respectivamente, para a realização das análises do índice meiótico e da palinologia.

\section{Índice meiótico}

Para a análise do processo meiótico, anteras provenientes de botões florais jovens foram utilizadas para a obtenção de meiócitos e tétrades. Desse modo, as mesmas foram submetidas à técnica de secagem ao ar adaptada para flores com tamanho reduzido (Viccini et al. 2006). As lâminas foram coradas com solução de Giemsa 5\%. O índice meiótico (IM) foi estimado de acordo com a seguinte fórmula proposta por LOVE (1949): IM= (Número de tétrades normais/Número total de tétrades) X100. Na análise, tétrades com quatro células de tamanho igual foram consideradas normais. Foram analisadas aproximadamente 1480 células.

\section{Viabilidade polínica e citoquímica}

Anteras oriundas de botões florais previamente fixados foram fragmentadas sobre as lâminas para a dispersão dos grãos de pólen. Para cada teste citoquímico, grãos de pólen assim obtidos foram submetidos a diferentes testes de coloração. Para a avaliação da viabilidade polínica, os mesmos foram corados com a solução de carmim acético 2\% (KEARNS \& INOUYE 1993) e a solução de Alexander (ALEXANDER 1980). Foram avaliadas cinco lâminas e 300 grãos de pólen por lâmina em cada teste. Após a contagem, o percentual de coloração dos grãos de pólen foi calculado. Os dados obtidos, por sua vez, foram empregados para a determinação do percentual de viabilidade polínica. Para lâminas coradas com carmim acético, foram considerados viáveis, os grãos de pólen corados em vermelho, ao passo que os grãos incolores foram considerados inviáveis. Já em lâminas coradas com a solução de Alexander, grãos com coloração arroxeada foram considerados viáveis e os de coloração esverdeada, inviáveis.

Para a observação de componentes de reserva presentes nos grãos de pólen, os grãos de pólen foram submetidos ao reagente de Lugol e ao corante Sudan IV para a identificação de amido e lipídeos de reserva, respectivamente. Foram analisadas cinco lâminas/corante e cinco campos/lâmina. As imagens dos meiócitos e dos grãos de pólen foram digitalizadas em microscópio de luz de epifluorescência BX-60 
acoplado com câmera digital Olympus DP73.

\section{Morfologia dos grãos de pólen}

Para a avaliação da morfologia polínica sob microscopia de luz de campo claro (ML), grãos de pólen oriundos de anteras previamente fixadas foram submetidos, por 24 horas ao tratamento com ácido acético P.A. Posteriormente, os mesmos foram acetolisados de acordo com o protocolo descrito por ERDTMAN (1960). As lâminas foram montadas em gelatina glicerinada. Os grãos de pólen foram mensurados por meio do software Olympus CellSens. Os eixos polar $(P)$ e equatorial $(E)$ foram medidos a partir de 25 grãos de pólen maduros. Valores de P/E foram calculados para cada grão de pólen medido. As terminologias e as classificações do tamanho e formato dos grãos de pólen, da morfologia da superfície polínica na visão equatorial e do número de aberturas foram adotados de acordo com as definições de ERDTMAN (1952), WILLARD et al. (2004) e de PUNT et al. (1994). Medidas da espessura da exina também foram realizadas para 10 grãos de pólen. As imagens dos grãos de pólen foram digitalizadas e mensuradas em microscópio de luz de epifluorescência BX-60 acoplado com câmera digital Olympus DP73.

Para uma visualização detalhada da ornamentação da exina, anteras provenientes de botões florais fixados em etanol: ácido acético 3:1 foram transferidas para microtubos contendo séries de desidratação em álcool etílico $(50 \%, 70 \%$ e $100 \%)$, sendo mantidas na última série até o preparo das amostras para Microscopia Eletrônica de Varredura (MEV). Para o preparo das amostras, uma gota de álcool etílico 100\% contendo as anteras foi depositada sobre stubs (suportes metálicos) contendo uma fita de carbono. Sob microscópio estereoscópio Leica EZ, cada antera foi cuidadosamente seccionada longitudinalmente, com o auxílio de agulhas histológicas, para a liberação dos grãos de pólen. Em seguida, foi adicionada, sobre os grãos de pólen uma gota de HDMS (Hexamethyldisilazane) para auxiliar na desidratação dos mesmos. Os stubs contendo as amostras foram colocados em dessecador. Doze horas após a secagem, os suportes foram levados ao Sputtering (SCD050) para a metalização dos grãos de pólen com ouro. Imagens digitalizadas foram obtidas no microscópio eletrônico de varredura JEOL JSM-6390LV.

\section{RESULTADOS E DISCUSSÃO}

\section{Índice meiótico}

O índice meiótico é um dado complementar a análise meiótica, sendo portanto, um indicador de regularidade. Elevadas instabilidades meióticas associadas a anormalidades cromossômicas resultam na formação de plantas atípicas, macho-estéreis ou incapazes de formação de grãos de pólen, podendo prejudicar a obtenção dos padrões mínimos exigidos para a produção de sementes assim como afetar a polinização (POZZOBON et al. 2011).

Os indivíduos de E. involucrata analisados no presente estudo apresentaram índices meióticos superiores a $95 \%$. Na Figura 1 são evidenciadas células meióticas em diferentes estágios e tétrades normais de $E$. involucrata. A Figura $1 \mathrm{~A}$ mostra uma diacinese, onde são observados 11 bivalentes, indicando que a espécie apresenta $2 n=2 x=22$ cromossomos, confirmando o número cromossômico relatado na literatura para a espécie (GUERRA et al. 2016). Nessa fase foi observado também que três pares de cromossomos se encontram associados ao nucléolo, indicando que seis cromossomos apresentam regiões organizadoras do nucléolo. Na Figura 1B é evidenciada a metáfase I, fase na qual os cromossomos, no seu grau máximo de condensação alcançam o equador da célula. A Figura $1 \mathrm{C}$ ilustra uma telófase I, onde ocorre a separação dos cromossomos homólogos que se direcionam aos polos opostos da célula. Na Figura 1D é evidenciada uma célula em metáfase II. A Figura 1E mostra uma telófase II. Em 1F, é observada uma tétrade normal, onde se visualizam os quatro núcleos filhos resultantes do processo meiótico. Na Figura 1G são observados quatro micrósporos formados, nas quais cada um originaria um grão de pólen. A Figura $1 \mathrm{H}$ mostra um grão de pólen jovem resultante do processo de divisão meiótica.

De acordo com LOVE (1949) plantas que apresentam índices meióticos superiores a 90\% podem ser consideradas citologicamente estáveis, pois quanto maior o índice meiótico, mais regular é o processo meiótico.

Os dados obtidos no presente estudo são similares aos relatados por FRANZON \& RASEIRA (2004) que realizaram análises em acessos provenientes do Rio Grande do Sul. Tais autores relataram um índice meiótico de $87,3 \%$. No mesmo trabalho foram identificados percentuais de tétrades normais para outras mirtáceas nativas, nos quais foram encontrados valores variando de $84,8 \%$ a $96,3 \%$. Além disso, estudos meióticos realizados por GUERRA et al. (2016) evidenciaram a presença de células meióticas regulares em $82,12 \%$ das células analisadas. Adicionalmente, o presente estudo constitui o primeiro relato de análises dessa natureza para genótipos provenientes do estado de Santa Catarina. Desse modo, pode-se inferir que os indivíduos de E. involucrata analisados são meioticamente estáveis com produção de gametas 
masculinos balanceados, apresentando, portanto, potencial para uso como genótipos em programas de melhoramento genético.

A
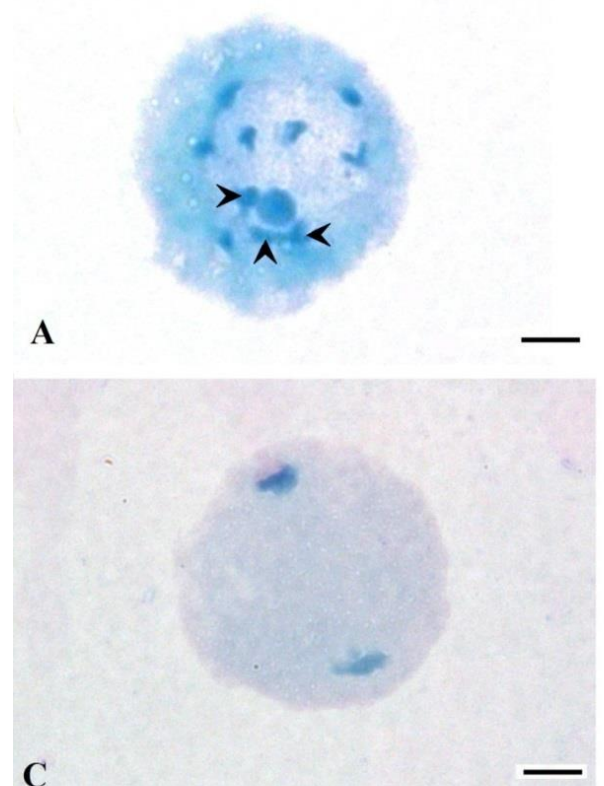

C

E

G

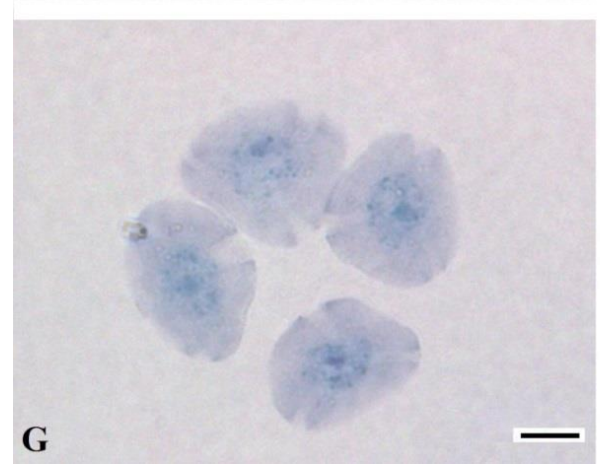

B

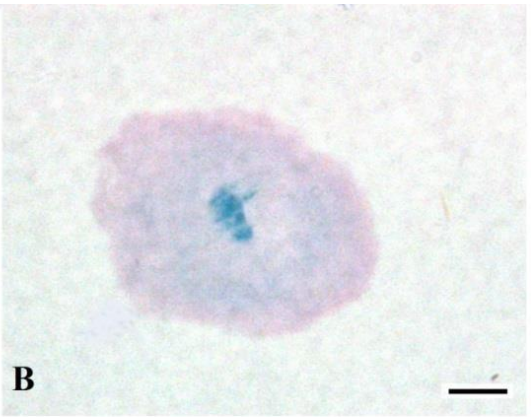

D

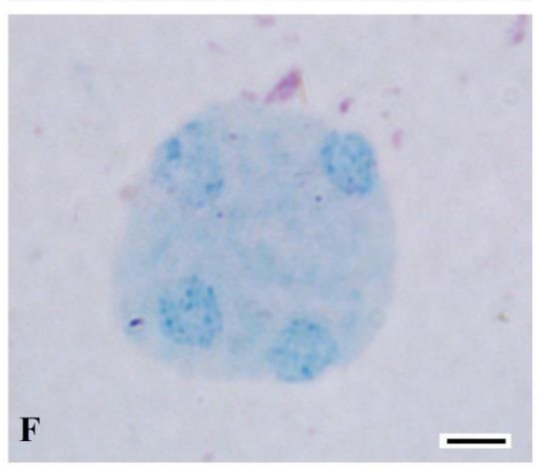

H

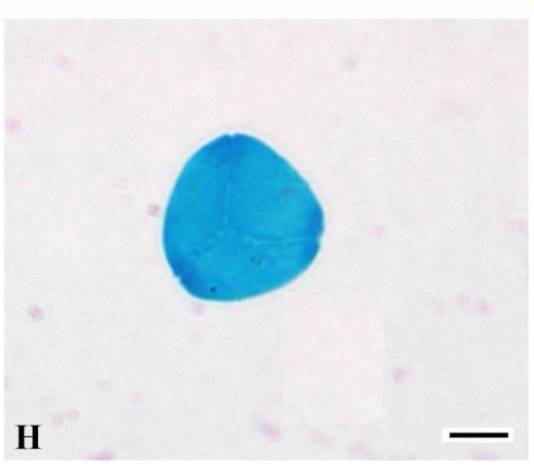

Figura 1. Células meióticas e grãos de pólen jovens de Eugenia involucrata. A) Diacinese com três pares de cromossomos associados ao nucléolo (setas). B) Metáfase I. C) Telófase I. D) Metáfase II. E) Telófase II. F) Tétrade regular. G) Quatro micrósporos. H) Grão de pólen imaturo. Barras $=10 \mu \mathrm{m}$.

Figure 1. Meiotic cells and young pollen grains of Eugenia involucrata. A) Diakinesis with three pairs of chromosomes associated to the nucleolus (arrows). B) Metaphase I. C) Telophase I. D) Metaphase II. E) Telophase II. F) Regular tetrad. G) Four microspores. H) Immature pollen grain. Bars $=10 \mu \mathrm{m}$.

\section{Viabilidade polínica e citoquímica}

Informações sobre a viabilidade do pólen são essenciais para a conservação e caracterização de germoplasma, assim como para o melhoramento genético, uma vez que as taxas de viabilidade polínica estão associadas ao comportamento meiótico.

Os resultados obtidos indicam que os corantes empregados foram eficientes para a determinação dos índices de viabilidade polínica. De um total de 2016 grãos de pólen avaliados com auxílio do método de coloração com carmim acético $2 \%$ obteve-se um percentual médio de viabilidade igual a $96 \%$. No teste colorimétrico com Alexander observou-se 2521 grãos de pólen, dos quais se obteve uma viabilidade média 
igual a 98\%. A Figura 2 mostra grãos de pólen de E. involucrata submetidos aos diferentes corantes. Os altos índices de viabilidade estão de acordo com a regularidade do processo meiótico observado para a espécie no presente estudo.
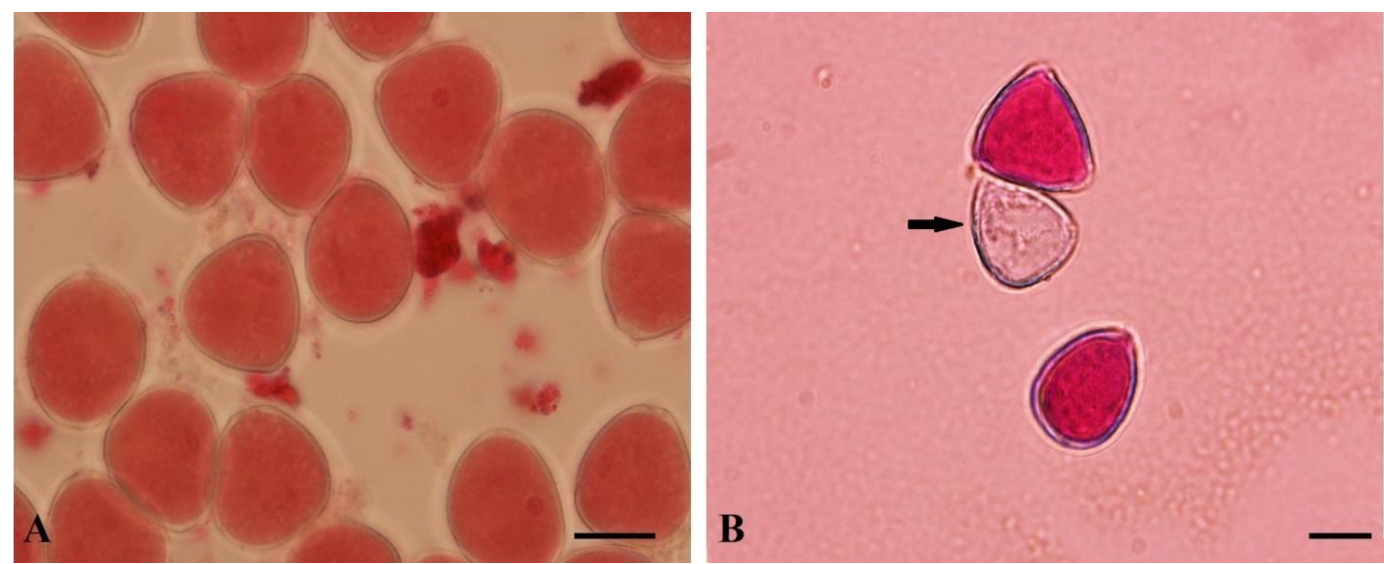

Figura 2. Grãos de pólen de Eugenia involucrata submetidos a testes colorimétricos para a avaliação da viabilidade polínica. A) Grãos de pólen viáveis corados com carmim acético 2\%. B) Grãos de pólen viáveis e inviável (seta) corados com solução de Alexander. Barras $=10 \mu \mathrm{m}$.

Figure 2. Pollen grains of Eugenia involucrata subjected to colorimetric tests for pollen viability analysis. A) Viable pollen grains stained with acetic carmine $2 \%$. B) Viable and non-viable (arrow) pollen grains stained with Alexander solution. Bars $=10 \mu \mathrm{m}$.

Os testes colorimétricos com Lugol e Sudan IV possibilitaram constatar que os grãos de pólen de $E$. involucrata apresentam amido como substância de reserva, uma vez que com o Lugol, os grãos de pólen adquiriram coloração marrom-avermelhada (Figura 3A). A coloração com Sudan IV permitiu identificar que os grãos de pólen são lipídio negativos, já que os grãos permaneceram incolores, mesmo após o tratamento com o corante (Figura 3B).

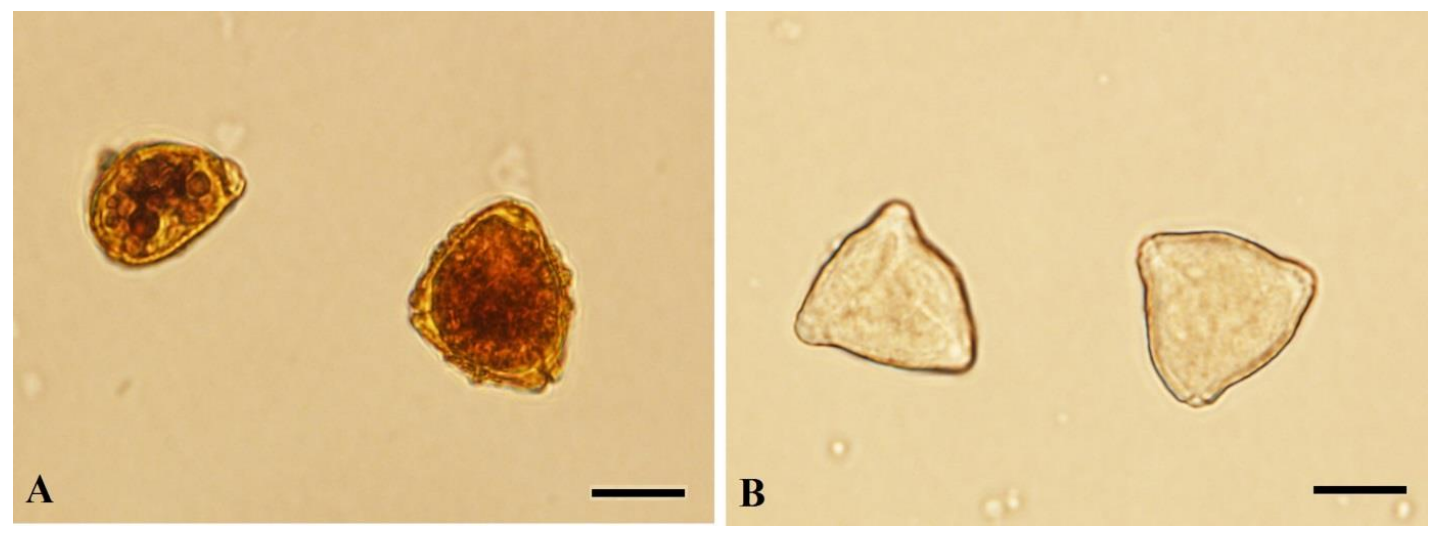

Figura 3. Grãos de pólen de Eugenia involucrata submetidos a testes citoquímicos. A) Grãos de pólen amido positivos corados com Lugol. B) Grãos de pólen lipídeos negativos tratados com Sudan IV.

Barras $=10 \mu \mathrm{m}$.

Figure 3. Pollen grains of Eugenia involucrata subjected to cytochemistry tests. A) Starch-positive pollen grains stained with Lugol's iodine. B) Lipid-negative pollen grains treated with Sudan IV.

Bars $=10 \mu \mathrm{m}$.

A presença de amido como substância de reserva é considerada importante na manutenção da viabilidade do grão de pólen, pois o amido é totalmente ou parcialmente convertido em glicose, frutose, sacarose e pectinas que aumentam a sua resistência em ambientes hostis, bem como auxiliam na germinação do tubo polínico (RODRÍGUEZ-GARCíA et al. 2003, PACINI et al. 2006).

Já a presença de lipídeos está relacionada à adesão dos grãos de pólen à antera e ao estigma, à proteção dos grãos de pólen contra a perda de água e radiação UV, além da manutenção dos grãos de pólen unidos durante o transporte por insetos (PACINI \& HESSE 2005). De acordo com os resultados do presente estudo, os lipídeos parecem não ser importantes na adesão dos grãos de pólen durante a 
polinização nessa espécie, já que a mesma apresentou grãos lipídeo negativos. De acordo com REGO et al. (2006), no período da antese, E. involucrata é visitada por abelhas (Apis melifera), sendo este considerado o principal vetor de polinização da espécie. Estudos indicam que algumas características morfológicas dos grãos de pólen estão associadas ao tipo de polinização. Por exemplo, flores polinizadas pelo vento possuem grãos de pólen secos, com tamanho moderado, superfície psilada, ou seja, sem ornamentações e são produzidos em grandes quantidades. Por outro lado, flores polinizadas por animais, como é o caso das flores de E. involucrata, possuem grãos de pólen ricos em materiais adesivos encontrados ao redor dos grãos de pólen (pollenkitt) ou outras substâncias, geralmente apresentam superfícies ornamentadas, tamanhos diversificados e são produzidos em quantidades variáveis (PACINI \& FRANCHI 1998). Desse modo, já que a espécie apresenta grãos de pólen lipídeo negativos, outras características polínicas, tais como o tamanho e a ornamentação, podem auxiliar na adesão dos mesmos durante o transporte pelas abelhas. Deve-se considerar também que as abelhas são os polinizadores mais versáteis e bem adaptados no transporte de grãos de pólen (JONES \& JONES 2001).

\section{Morfologia dos grãos de pólen}

De acordo com ERDTMAN (1952), Myrtaceae pode ser considerada uma família homogênea ou estenopolínica, ou seja, apresenta baixa diversidade polínica. Estudos realizados por BARTH \& BARBOSA (1972), que avaliaram 140 espécies da família, demonstram que variações polínicas em Myrtaceae estão limitadas a características secundárias, tais como detalhes no tipo de colpo, ornamentação da exina nos mesocolpos e apocolpos, espessura da exina, tamanho e forma dos grãos de pólen. Em um trabalho realizado por WYK \& DEDEKIND (1985) foi relatada a morfologia e o valor taxonômico dos grãos de pólen de 14 espécies sul-africanas pertencentes ao gênero Eugenia. Os autores indicaram que todas as espécies apresentaram morfologia polínica típica de espécies da família Myrtaceae, possuindo, dentre outras características, ornamentação verrucada ou rugulada o que não possibilitou a utilização de caracteres polínicos na diferenciação das 14 espécies do gênero, reforçando o caráter estenopalinológico da família.

No Brasil, um estudo em diferentes espécies do gênero Eugenia foi realizado por STANSKI (2014). Foram avaliadas seis espécies da região dos Campos Gerais, Paraná: E. arenosa, E. handroana, E. hiemalis, E. pitanga, E. punicifolia e E. uniflora. Foram encontradas espécies com três aberturas polínicas, além de outras variações no número de aberturas (quatro a cinco cólporos), valores de P/E entre 0,85 a 0,93, caracterizando-se a forma polínica como oblato-esferoidal, além de variações na ornamentação da exina que se apresentou areolada, granulada, psilada e escabrada. De acordo com a autora, diferenças significativas na morfologia polínica indicam que o gênero Eugenia pode ser considerado euripolínico, ou seja, com alta diversidade.

Relatos na literatura sobre a biologia polínica de E. involucrata estão concentrados principalmente em informações sobre a viabilidade polínica estimada por métodos colorimétricos ou in vitro. Estudos sobre a morfologia e ornamentação dos grãos de pólen são escassos, havendo apenas dois relatos na literatura realizados por BARTH \& BARBOSA (1972) e TAKEDA et al. (2002), que descreveram a morfologia polínica da espécie por meio de microscopia de luz em catálogos polínicos a partir de espécimes ocorrentes em Santa Catarina e no Parque Estadual de Vila Velha, Paraná, respectivamente. De acordo com esses autores, E. involucrata apresenta grãos de pólen tricolporados. Informações adicionais tais como a classificação do agrupamento, simetria e âmbito não foram descritas. Além disso, análises do padrão de ornamentação da exina nos referidos trabalhos não foram realizadas por meio de microscopia eletrônica de varredura, que permite a obtenção de imagens com maior poder de resolução, auxiliando na descrição mais detalhada da ornamentação polínica, quando comparada a imagens obtidas por meio de microscopia de luz. No presente estudo, as análises morfométricas possibilitaram a descrição dos grãos de pólen de $E$. involucrata como indicados na Tabela 1.

Alguns dados morfológicos obtidos no presente estudo, tais como o tamanho polínico, o número e tipo de aberturas corroboram as informações descritas por BARTH \& BARBOSA (1972) e TAKEDA et al. (2002).

Com relação à forma polínica, foram encontradas algumas discordâncias. No presente estudo foi identificado que a cerejeira-do-mato apresenta grãos oblatos, como relatado por BARTH \& BARBOSA (1972). Porém, ambos os relatos discordam com a descrição realizada por TAKEDA et al. (2002) que classificaram os pólens da espécie como peroblatos.

Quanto à ornamentação da superfície polínica, os dados do presente estudo também são similares à descrição realizada por BARTH \& BARBOSA (1972), que descrevem, por meio de ML, a presença de granulações médias na exina dos grãos de pólen da cerejeira-do-mato. Tais granulações correspondem à ornamentação verrucada observada por meio de MEV no presente estudo. Por outro lado, TAKEDA et al. 
(2002) relataram para a espécie a ausência de ornamentações na superfície polínica, classificando os grãos de pólen da espécie como psilados. Discordâncias em relação à forma e ornamentação polínicas para $E$. involucrata podem ter ocorrido devido a variações intraespecíficas. Os espécimes avaliados por TAKEDA et al. (2002) foram provenientes de populações provenientes do estado do Paraná, ao passo que os espécimes avaliados por BARTH \& BARBOSA (1972) e pelo presente estudo foram coletados em populações catarinenses.

Tabela 1. Características polínicas de Eugenia involucrata.

Table 1. Pollen characteristics of Eugenia involucrata.

\begin{tabular}{|c|c|}
\hline Morfometria & Valores médios (valor mín-valor máx) \\
\hline Eixo polar $(\mathrm{P})(\mu \mathrm{m})$ & $12,04(10,35-12,26)$ \\
\hline Eixo equatorial $(E)(\mu m)$ & $20,62(17,42-24,85)$ \\
\hline $\mathrm{P} / \mathrm{E}$ & 0,58 \\
\hline Espessura da exina $(\mu \mathrm{m})$ & $1,62(1,26-2,10)$ \\
\hline Comprimento do colpo ( $\mu \mathrm{m})$ & $3,61(2,47-4,35)$ \\
\hline Morfologia & Características \\
\hline Agrupamento & Mônades \\
\hline Tamanho & Pequeno \\
\hline Forma & Oblato \\
\hline Polaridade & Isopolar \\
\hline Simetria & Radial \\
\hline Âmbito & Triangular \\
\hline Número e Tipo de aberturas & Tricolporado, sincolpado \\
\hline Ornamentação & Verrucada \\
\hline
\end{tabular}

A Figura 4 ilustra a morfologia polínica de E. involucrata na qual os grãos, visualizados sob ML e MEV estão representados em vistas polar (Figura 4C e 4E) e equatorial (Figuras 4B e 4D). Nas imagens é possível observar a forma e as três aberturas polínicas, além da ornamentação verrucada na superfície da exina.

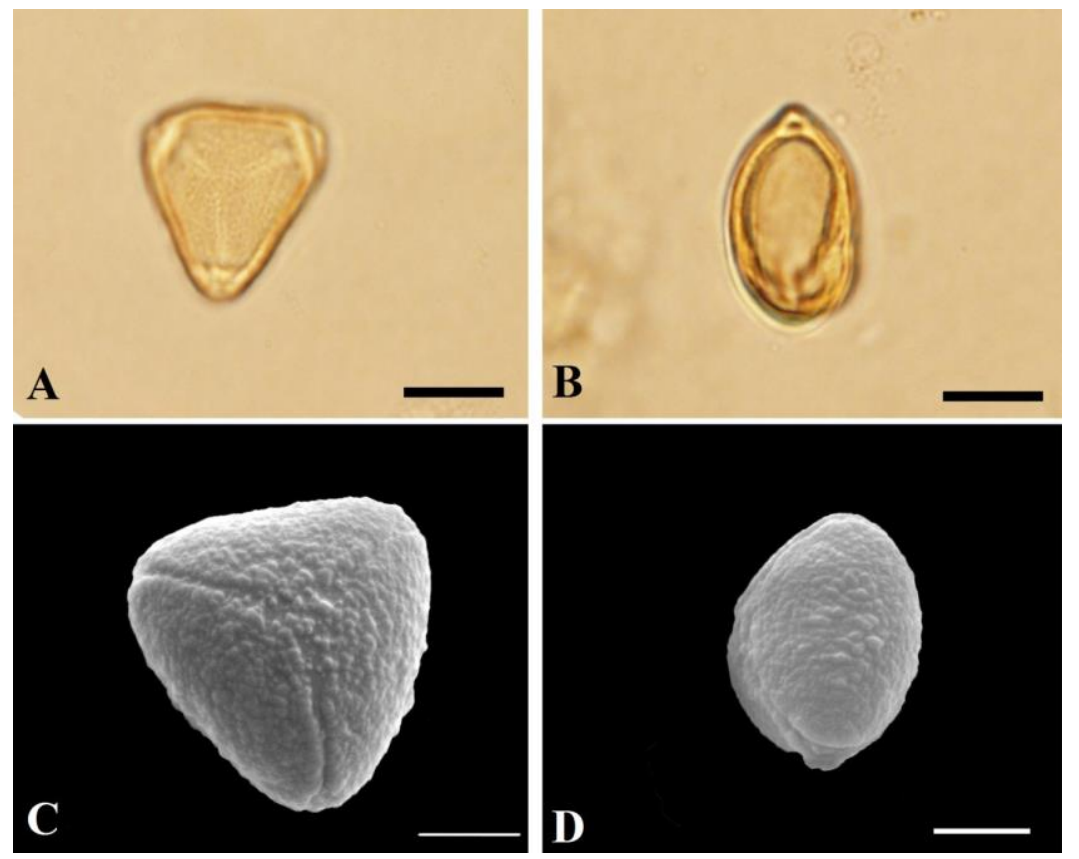

Figura 4. Grãos de pólen de Eugenia involucrata visualizados sob diferentes tipos de microscopia. A) Vista polar de um grão de pólen acetolisado visualizado sob ML. B) Vista equatorial de um grão de pólen acetolisado visualizado sob ML. C) Vista polar de um grão de pólen visualizado sob MEV, na qual é possível observar a ornamentação verrucada na superfície polínica. D) Vista equatorial de um grão de pólen visualizado sob MEV. Barras $=10 \mu \mathrm{m}$ (Figuras A e B) e $5 \mu \mathrm{m}$ (Figuras C e D).

Figure 4. Pollen grains of Eugenia involucrata displayed under different types of microscopy. A) Polar view of an acetolyzed pollen grain under LM. B) Equatorial view of an acetolyzed pollen under LM. D) Polar view of a pollen grain with verrucate ornamentation under SEM. E) Equatorial view of a pollen grain under SEM. Bars = 10 $\mu$ m (Figures $A$ and B); $5 \mu m$ (Figures $C$ and $D$ ). 
As discordâncias na forma e padrão de ornamentação da exina dos grãos de pólen de E. involucrata relatadas no presente estudo demonstram a ocorrência de variações intraespecíficas, o que evidencia que embora a família seja considerada estenopalinológica, o gênero Eugenia pode ser considerado euripolínico, ou seja, com alta diversidade, como relatado por STANSKI (2014).

Com relação a aspectos ecológicos, a presença de exina verrucada na superfície polínica de $E$. involucrata está associada à polinização entomófila (por abelhas) que a espécie apresenta, já que de acordo com SANNIER et al. (2009) a grande diversidade dos tipos de ornamentação nos grãos de pólen das angiospermas às vezes é relacionada à diversidade nos sistemas de polinização, sugerindo-se que grãos de pólen psilados estão associados à polinização pelo vento ou água, ao passo que grãos de pólen ornamentados são associados à polinização biótica.

\section{CONCLUSÃO}

Os dados disponibilizados no presente estudo podem ser utilizados como informações auxiliares a futuros programas de melhoramento genético, auxiliando na escolha de materiais genéticos potenciais, tendo em vista o reconhecimento da regularidade e estabilidade meióticas e alta viabilidade polínica constatadas para $E$. involucrata. Além disso, os dados sobre a morfologia polínica mostraram a ocorrência de variações intraespecíficas, evidenciando o caráter euripalinológico do gênero Eugenia, constituindo de importantes informações para a biossistemática. Os mesmos auxiliaram ainda na disponibilização de dados inéditos sobre a ecologia relacionada a mecanismos de polinização na espécie, mostrando que a mesma possui grãos de pólen amido positivos que funcionam como uma estratégia para a manutenção da viabilidade dos mesmos e possuem grãos de pólen lipídeo negativos, evidenciando que essa substância de reserva não é fundamental para a adesão dos grãos de pólen ao tubo polínico. Adicionalmente, a observação da ornamentação polínica verrucada, que é associada à polinização biótica, está relacionada à polinização entomófila que a espécie apresenta. A realização do presente estudo configura-se como mais uma forma estratégica de promover a valorização e conservação de recursos genéticos nativos do Brasil.

\section{REFERÊNCIAS}

ALEXANDER MP. 1980. A versatile stain for pollen fungi, yeast and bacteria. Stain Technology 55: 13-18.

BAKER HG \& BAKER I. 1979. Starch in angiosperm pollen grains and its evolutionary significance. American Journal of Botany 66: 591-600.

BARTH OM \& BARBOSA AF. 1972. Catálogo sistemático de pólens das plantas arbóreas do Brasil meridional XV Myrtaceae. Memórias do Instituto Oswaldo Cruz 70: 467-496.

BEDINGER P. 1992. The remarkable biology of pollen. The Plant Cell 4: 879-887.

BLACKMORE S. 2007. Pollen and spores: Microscopic keys to understanding the earth's biodiversity. Plant Systematics and Evolution 263: 3-12.

CAMLOFSKI AMO. 2008. Caracterização do fruto de Cerejeira (Eugenia involucrata DC) visando seu aproveitamento tecnológico. Dissertação (Mestrado em Ciência e Tecnologia de Alimentos). Ponta Grossa: UEPG. 102p.

DEGENHARDT $\mathrm{J}$ et al. 2007. Cerejeira-do-Mato (Eugenia involucrata). Pelotas: Embrapa Clima Temperado. 22p. (Documentos 211).

DIEGUES IP et al. 2015. Comportamento meiótico e viabilidade polínica na espécie Jatropha curcas L. Semina: Ciências Agrárias 36: 141-150.

ERDTMAN G. 1952. Pollen Morphology and Plant Taxonomy: Angiosperms. Stockholm: Almqvist and Wiksell. 539p.

ERDTMAN G. 1960. The acetolysis method, a revised description. Svensk Botanisk Tidskrift 54: 561-564.

FRANZON RC \& RASEIRA MCB. 2004. Meiotic index in Myrtaceae native fruits trees from southern Brazil. Crop Breeding and Applied Biotechnology 4: 344-349.

GRANATO LM. 2010. Comportamento meiótico em híbridos de café arabusta (C. arabica cv bourbon vermelho x $C$. canephora cv robusta). Dissertação (Mestrado em Genética, Melhoramento Vegetal e Biotecnologia). Campinas: IAC. $91 \mathrm{p}$.

GUERRA D et al. 2016. Genetic and cytological diversity in cherry tree accessions (Eugenia involucrata DC) in Rio Grande do Sul. Crop Breeding and Applied Biotechnology 16: 219-225.

HARON NW \& MOORE DM. 1996. The taxonomic significance of leaf micromorphology in the genus Eugenia L. (Myrtaceae). Botanical Journal of the Linnean Society 120: 265-277.

HEYWOOD VH et al. 2007. Flowering plant families of the world. Canada: Firefly Books. 424p.

JONES GD \& JONES SD. 2001. The uses of pollen and its implication for entomology. Neotropical Entomology 30: 341 350.

KEARNS CA \& INOUYE DW. 1993. Techniques for pollination biologists. Niwot: University Press of Colorado. 583p.

LORENZI H. et al. 2006. Eugenia involucrata DC. In: LORENZI H. et al. (Eds). Frutas brasileiras e exóticas cultivadas (de consumo in natura). Nova Odessa: Plantarum. p. 198-199.

LOVE RM. 1949. Estudos citológicos preliminares de trigos rio-grandenses. Porto Alegre: Secretaria do Estado dos 
Negócios da Agricultura, Indústria e Comércio. 23p. (Circular, 74).

NEPI M \& FRANCHI GG. 2000. Cytochemistry of mature angiosperm pollen. Plant Systematics and Evolution 222: 4562.

PACINI E \& FRANCHI GG. 1998. Pollen dispersal unit, gynoecium and pollination. In: OWENS SJ \& RUDALL PJ. (Eds). Reproductive biology in systematics, conservation and economic botany. Kew: Royal Botanical Gardens. p. 183-195.

PACINI E \& HESSE M. 2005. Pollenkitt - its composition and functions. Flora 200: 399-415.

PACINI E et al. 2006. Pollen carbohydrates and water content during development, presentation, and dispersal: a short review. Protoplasma 228: 73-77.

POZZOBON MT et al. 2011. Meiose e viabilidade polínica em linhagens avançadas de pimenta. Horticultura Brasileira 29: 212-216.

PRADO AP. 2009. Aspectos autoecológicos e silviculturais de Eugenia involucrata DC. Dissertação (Mestrado em Silvicultura). Santa Maria: UFSM. 118p.

PUNT W et al. 1994. Glossary of pollen and spore terminology. Uthrecht, L.P.P. Foundation. Disponível em: http://www.bio.uu.nl/ palaeo/glossary/glos-int.html. Acesso em: 26 out. 2016.

REGO GM et al. 2006. Monitoramento dos Estádios Fenológicos Reprodutivos em Cerejeira-do-Mato. Colombo: Embrapa Florestas. 5p. (Comunicado Técnico, 171).

RODRÍGUEZ-GARCÍA MI et al. 2003. Behavior of storage lipids during development and germination of olive (Olea europaea L.) pollen. Protoplasma 221: 237-244.

SÁNCHEZ-VINDAS PE et al. 2001. Myrtaceae. In: STEVENS WD et al. (Eds.) Flora de Nicaragua. Angiospermas: Fabaceae-Oxalidaceae. 85. Monographs in Systematic Botany from the Missouri Botanical Garden, Missouri. p.15641580.

SANNIER $\mathrm{J}$ et al. 2009. A comparative analysis of pollinator type and pollen ornamentation in the Araceae and the Arecaceae, two unrelated families on the monocots. BMC Research Notes 2: 145.

SHARPE RH et al. 1996. Cherry of Rio Grande. Proceedings of Florida State Horticulture Society 109: 220-221.

SOBRAL M et al. 2015. Myrtaceae in: Lista de Espécies da Flora do Brasil. Jardim Botânico do Rio de Janeiro, Rio de Janeiro, 10 de jan. 2014. Disponível em: http://floradobrasil.jbrj.gov.br. Acesso em: 10 nov. 2017.

STANSKI C. 2014. Catálogo polínico de espécies de Myrtaceae e Solanaceae da região dos Campos Gerais - Paraná, Brasil. Dissertação (Mestrado em Engenharia Florestal). Curitiba: UFPR. 183p.

TAKEDA IJM et al. 2002. Catálogo polínico do parque estadual de Vila Velha, Paraná - 3ª parte. Arquivos de Ciências da Saúde Unipar 6: 61-66.

VAN DER MERWE MM et al. 2005. Molecular phylogenetic analysis of Eugenia L. (Myrtaceae), with emphasis on southern African taxa. Plant Systematics and Evolution 251: 21-34.

VICCINI LF et al. 2006. Chromosome numbers in the genus Lippia (Verbenaceae). Plant Systematics and Evolution 256: 171-178.

WANG YQ et al. 2004. Pollen Histochemistry and Pollen: Ovule Ratios in Zingiberaceae. Annals of Botany 94: 583-591.

WYK AEV \& DEDEKIND I. 1985. The genus Eugenia (Myrtaceae) in southern Africa: Morphology and taxonomic value of pollen. South African Journal of Botany 51: 371-378.

WILLARD DA et al. 2004. Atlas of pollen and spores of the Florida everglades. Palynology 28: 175-227.

WILSON PG. 2011. Myrtaceae. In: KUBITZKI K. (Ed.). The families and genera of vascular plants: Flowering plants. Eudicots. Berlin: Springer. p. 212-271. 